\title{
Buprenorphine in the Treatment of Severe Major Depression with Severe Suicidal Temptations
}

\author{
Jamshid Ahmadi ${ }^{1 *}$, Seyed Ali Dastgheib ${ }^{1}$ and Saxby Pridmore ${ }^{2}$ \\ ${ }^{1}$ Substance Abuse Research Center, Shiraz University of Medical Sciences, Iran \\ ${ }^{2}$ Department of Psychiatry, University of Tasmania, Australia
}

Submission: April 22, 2017; Published: April 28, 2017

*Corresponding author: Jamshid Ahmadi, Professor of Psychiatry, Founder and Director, Substance Abuse Research Center,Shiraz University of Medical Sciences, Shiraz, Iran, Tel: +98-71-3627 93 19, E-mail: Jamshid_Ahmadi@yahoo.com

\begin{abstract}
Background: Administration of high dose of buprenorphine is associated with rapid-acting anti-depressive and ant-suicidal effects.

Objective: To examine the effect of high dose buprenorphine on the refractory major depression with severe suicidal tendencies.

Method: In the current study we tested the competency of buprenorphine for the treatment of depression and suicide.

Results: High dose buprenorphine was resulted to fast treatment of refractory depression and suicide. Moreover, promotionin psychoactivity, high demotion in depression, regulation of emotion and mood, were observed following buprenorphine administration. Buprenorphine was well tolerated as well.
\end{abstract}

Discussion: Our results illuminated that buprenorphine hasrapid and sustained antidepressive potentials. These findings should be replicated in randomized, placebo-controlled, double-blind trials.

Conclusion: This report indicated that a single high dose of buprenorphine appears to be clinically effective and safe. Our study advises that a single high dose buprenorphine can provide a speedy, simple and safe means of treatment of depression and suicide. Usage of a single high dose of buprenorphine appears to concerns about compliance, and also to diminish the chance of buprenorphine being diverted for abuse.

Keywords: Refractory depression; Suicidal tendencies; Buprenorphine

\section{Introduction}

The majority of patients with substance use disorders have high grade of depression, suicide and anxiety [1-3]. Moreover, they could have minor psychopathology $[4,5]$ and also personality disorders[6,7]. It should be emphasized that primary psychiatric symptomatology can predict the rate of failure or success in detoxification treatment of substance dependents [8]. Mood disorders could intervene with the course and prognosis of substance dependence. Furthermore, studies indicated that opioid dependent patients having a depressed mood at the beginning of therapy may be less likely to be clean at follow-up than those with a normal mood [9]. Some of the drugs or substances like ketamine, buprenorphine or Ayahuasca, can lower the level of depression and also raise and expand the mood state $[10,11]$.

Various studies uncovered that buprenorphine can shorten the level of depression and suicidal temptations rapidly $[12,13]$.
The trials needed to validate that it is effective have not been completed yet. Since buprenorphine is possibly addicting itself, thus it should not be commonly used for this intent. Further studies are required to test this area [12-14]. Diseases related to mental health have been raising universally [12-18]. In mental problems, substance connected disorders, especially depressive disorders have been considered as increasing global problems. At the present time, substance induced psychiatric presentations to inpatient and outpatient centers are going up problems [19-48].

Buprenorphine is usually applied to treat withdrawal symptoms of opioids and pain syndromes as well [13]. Now, we are considering buprenorphine as a new indication and practice for the cessation or reduction of refractory major depressive disorders and severe suicidal desires, because we contemplate that (our rationale) biochemistry underlies in opioid dependence is mainly similar to depression, in both groups the endogenous 


\section{Global Journal of Addiction \& Rehabilitation Medicine}

opioid system is disturbed and the amount of catecholamine's, endorphins and enkephalins has be undiminished $[12,13]$.

\section{Results}

Administration of high dose of buprenorphine would result to rapid treatment of resistant/refractory depression and also suicide. Furthermore, high demotion in depression, regulation of emotion and mood, and promotion in psychoactivity were seen following buprenorphine application. Moreover, buprenorphine was well tolerated.

\section{Discussion}

Ultra high doses of buprenorphine ( 32 and then $128 \mathrm{mg}$ ) had a safe, speedy and suitable influence oncessation or reduction of severe intractable depression and severe refractory suicidal impulsions [49]. Usage of buprenorphine in these serious conditions has not been advised earlier.

\section{Conclusion}

It may be supposed that an ultra high dose of buprenorphine has fast and safe effect on these serious and emergency situations. This could be a novel inference.

\section{References}

1. Rounsaville BJ, Weissman MM, Kleber H, Wilber C (1982) Heterogeneity of psychiatric diagnosi= in treated opiate addicts. Arch Gen Psychiatry 39: 161-166.

2. Dorus W, Senay EC (1980) Depression, demographic dimensions, and drug abuse. Am J Psychiatry 137: 699-704.

3. Ross HE, Glaser FB, Germanson T (1988) The prevalence of psychiatric disorders in patients with alcohol and other drug problems. Arch Gen Psychiatry 45: 1023-1031.

4. Swift W, Williams G, Neill O, Grenyer B (1990) The prevalence of minor psychopathology in opioid users seeking treatment. Br J Addict 85: 629-634.

5. Darke S, Wodak A, Hall W, Heather N, Ward J (1992) Prevalence and predictors of psychopathology among opioid users. Br J Addict 87: 771-776.

6. Nace EP, Davis CW, Gaspari JP (1991) Axis II co-morbidity in substance abusers. Am J Psychiatry 148: 118-120.

7. Dejong CAJ, Van Den Brink W, Harteveld FM, Van Der Wielen EGM (1993) Personality disorders in alcoholics and drug addicts. Comprehensive Psychiatry 34: 87-94.

8. Kosten TR, Rounsaville BJ, Kleber HD (1982) DSM-III personality disorders in opiate addicts. Compr Psychiatry 23: 572-581.

9. Rounsaville BJ, Kosten T, Kleber H (1985) Success and failure at outpatient opioid detoxification. Evaluating the process of clonidineand methadone-assisted withdrawal. J Nerv Ment Dis 173: 103-110.

10. OsórioFde L, Sanches RF, Macedo LR, Santos RG, Maia-de-Oliveira JP, et al. (2015) Antidepressant effects of a single dose of ayahuasca in patients with recurrent depression: a preliminary report. Rev Bras Psiquiatr 37(1):13-20.

11. Sanches RF, de Lima Osório F, Dos Santos Sanches RF (2016) Antidepressant Effects of a Single Dose of Ayahuasca in Patients with Recurrent Depression: A SPECT Study 1496. 36(1): 77-81.
12. Ahmadi J (2016) Fast Treatment of Methamphetamine Related Anxiety and Depressive Disorders: A Novel Approach. J Addict Med Ther Sci 1(2): 044-046.

13. Sadock B, Sadock V, Ruiz P (Editors) (2015) Kaplan \& Sadock'S Synopsis of Psychiatry: Lippinott Wiliams and Wilkins, Philadelphia, USA.

14. Gracer R (2007) The Buprenorphine Effect on Depression.The National Alliance of Advocates for Buprenorphine Treatment(NAABT) newsletter.

15. Ahmadi J, Ahmadi N, Soltani F, Bayat F (2014) Gender differences in depression Scores of Iranian and German medical students. Iran J Psychiatry Behav Sci 8(4): 70-73

16. Khademalhosseini Z,Ahmadi J, Khademalhosseini M (2015) Prevalence of Smoking, and its Relationship with Depression, and Anxiety in a Sample of Iranian High School Students. Enliven: Pharmacovigil Drug Saf 1(1): 005.

17. Ahmadi J (2015) Heroin Dependency Treatment: A New Approach. J Addict Depend 1(2): 1-3.

18. Ahmadi J Hashish (2015) Induced Olfactory Hallucination: A Novel Finding. J Psychiatry 18: 330.

19. Ahmadi J (2015) Excellent Outcome of Psychosis Induced by Methamphetamine Intoxication after 20 Sessions of Electro Convulsive Therapy. J Addict Depend 1(2): 1- 2.

20. Ahmadi J, Ekramzadeh S, Pridmore S (1793) Remission of Methamphetamine- Induced Withdrawal Delirium and Craving after Electroconvulsive Therapy. Iran J Psychiatry Behav Sci 9(4):e.

21. Ahmadi J Tramadol (2015) Dependency Treatment: A New Approach. J Addict Med Ther Sci 2(1): 001-03.

22. Ahmadi J, Pridmore S, Ekramzadeh S (2015) Successful Use Of Electro Convulsive Therapy in the Management of Methamphetamine Induced Psychosis with Onset During Intoxication. J Addict \& Depend 1: 1-3.

23. Ahmadi J (2015) The Effect of Buprenorphine and Bupropion in the Treatment of Methamphetamine Dependency and Craving. Br J Med \& Med Res 10 (2): 1-4.

24. Ahmadi J, Amiri A, Ghanizadeh A, Khademalhosseini M, Khademalhosseini Z, et al. (2014) Prevalence of Addiction to the Internet, Computer Games, DVD, and Video and Its Relationship to Anxiety and Depression in a Sample of Iranian High School Students. Iran J Psychiatry Behav Sci 8(2): 75-80.

25. Ahmadi J, Soltani F, Tabatabaee F (2014) Substance Use Disorders in Patients With Lung or Heart Diseases. Sch J App Med Sci 2(1A): 111120.

26. Ahmadi J, Sharifi M (2013) Lifetime and Current Prevalence of Tobacco Smoking. J. Addict Res Ther 4: 145.

27. Ahmadi J, Ahmed MG (2013) Dubai Medical College Students' Attitudes towards Substance Use. J Addict Res Ther S6: 005.

28. Ahmadi J, Keshtkar M, Pridmore S (2011) Methamphetamine Induced Synesthesia: A Case Report. Am J Addict 20: 306.

29. Ahmadi J, Naghshvarian M, Afshari R (2011) Opioid abuse in male population referred for mandatory Urine Opioid Screen before marriage in Shiraz-Iran. Iranian J Psychiatry Behav Sci 5(2): 126-130.

30. Ahmadi J, Ghanizadeh A (2000) Motivations for use of opiates among addicts seeking treatment in Shiraz. Psychol Rep 87(3 Pt 2): 11581164.

31. Ahmadi J, Khalili H, Jooybar R, Namazi N, Aghaei PM (2001) Cigarette smoking among Iranian medical students, resident physicians and attending physicians. Eur J Med Res 6(9): 406-408. 
32. Ahmadi J, Ahmadi M, Pridmore S (2005) Substance Use Disorders in Rheumatic Patients. German J Psychiatry 5 (8): 66-69.

33. Anvar M, Ahmadi J, Hamidian S, Ghafaripour S (2016) Female Sexual Dysfunction Among the Wives of Opioid-Dependent Males in Iran. Int J High Risk Behav Addict 5(1): e25435.

34. Ahmadi J, Sahraian A, Shariati S (2015) Delusional disorder joined with opium dependence. Sch J App Med Sci 3(9D): 3387-3390.

35. Ahmadi J, Dastgheib SA, Mowla A, Ahmadzadeh L, Bazrafshan A, et al. (2016) Treatment of Methamphetamine Induced Persistent Psychosis. J Add Pre Med 1(1): 103.

36. Ahmadi J (2016) Misuse of tablets of ephedrine, adult cold and cold stop to get high: A distinguished enigma. Int J Res Rep 2(2): 30-35.

37. Ahmadi J (2016) Methylphenidate in the treatment of methamphetamine withdrawal craving: a novel outcome. J Drug Abuse 2: 1-12.

38. Ahmadi J, Ghafoori M, Rahimi S (2015) Management of heroin addiction with baclofen and clonidine. Int J Res Rep 1(1): 6-10.

39. Ahmadi J (2016) Recurrent psychosis related to methamphetamine. J Harmoniz Res Med Hlth Sci 3(1): 51-55.

40. Kutz I, Reznik V (2001) Rapid heroin detoxification using a single high dose of buprenorphine. J Psychoactive Drugs 33(2): 191-193.

41. Ahmadi J, Khoddaman AR, Kordian S, Pridmore S (2016) Treatment of an obese opioid dependent with a single dose of $80 \mathrm{mg}$ of buprenorphine: a new opening. Int J Res Rep 2(1): 11-18.
42. Ahmadi J, Ahmadi F, Torabi A, Ahmadi S, Ahmadi F (2016) A single dose of $55 \mathrm{mg}$ of buprenorphine for the treatment of heroin dependence: a new result. J Haminiz Med Res and Hlth Sci 3(1): 1-7.

43. Ahmadi J (2016) Instant Detoxification of Heroin with High Dose of Buprenorphine. J Addiction Prevention 4(1): 3.

44. Ahmadi J, Sarani EM, Jahromi MS, Pridmore S (2016) Treatment of heroin dependence with $40 \mathrm{mg}$ of buprenorphine: a novel passageway. Int J Original Res 2(2): 68-73.

45. Ahmadi J (2016) Non-opioid drugs in the management of tramadol dependence: A novel approach. Int J Original Res 2(2): 40-45.

46. Ahmadi J, Ahmadi F, Ahmadi F, Ahmadi S, Pridmore S (2016) A firsthand launch: Heroin dependence treatment with a single dose of 48 mg of buprenorphine. Landmark Res J Med Med Sci 3(2): 019-022.

47. Ahmadi J (2016) Treatment of cannabis related psychosis with electroconvulsive therapy (ECT): a rapid approach. J Harmoniz Res Med and Hlth Sci 3(1): 44-50.

48. Ahmadi J (2016) Combination of analgesics (NSAIDS), baclofen, clonidine and a single dose of buprenorphine for heroin detoxification.

49. Ahmadi J (2017) Highdose of Buprenorphine in the Treatment of Refractory Major Depression with Severe Suicidal Tendencies. J Addict \& Depend 1: 1-3.

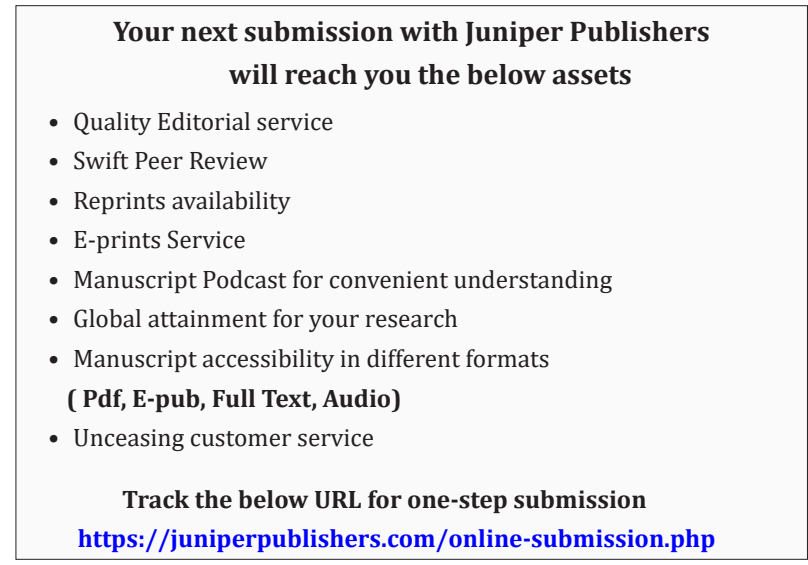

